\title{
Multiple Changes in Persistence vs. Explosive Behaviour: The Dotcom Bubble
}

\author{
Otavio R. de Medeiros ${ }^{1}$ \\ Vitor Leone ${ }^{2}$
}

\begin{abstract}
Based on a method developed by Leybourne, Kim and Taylor (2007) for detecting multiple changes in persistence, we test for changes in persistence in the dividend-price ratio of the NASDAQ stocks. The results confirm the existence of the so-called Dotcom bubble around the last turn of the century and its start and end dates. Furthermore, we compare the results with a test for detecting and date-stamping explosive unit-root behaviour developed by Phillips, Wu and Yu's (2011) also applied to the NASDAQ price and dividend indices. We find that Leybourne, Kim and Taylor's test is capable of detecting the Dotcom bubble as much as Phillips, $\mathrm{Wu}$ and Yu's test is, but there are significant differences between the bubble start and end dates suggested by both methods and between these and the dates reported by the financial media. We also find an unexpected negative bubble extending from the beginning of the 1970s to the beginning of the 1990s where the NASDAQ stock prices were below their fundamental values as indicated by their dividend yields, which has not been reported in the literature so far.
\end{abstract}

Keywords: Multiple changes in persistence, Explosive behaviour, Unit roots, Dotcom Bubble, NASDAQ.

JEL classifications: C10, C32, F15, G12, G14, G15

Corresponding Authors: Professor Otavio Ribeiro de Medeiros; University of Brasilia; Faculty of Economics, Administration and Accounting; Department of Accounting, otavio@unb.br

Dr Vitor Leone; Division Of Economics, Nottingham Trent University, vitor.leone@ntu.ac.uk

\section{First draft: do not cite or quote without written permission from authors}

\section{Introduction}

During the second half of the 1990s, led by stocks of firms from the new economy and internet sectors, the U.S. stock market experienced an impressive rise in its main indices, particularly the NASDAQ index. Associated with this remarkable rise, a lot of attention was focused on the effects of the internet and computing technology on productivity and the rise of a new information economy. The events which led to such extraordinary growth and subsequent dramatic fall in prices have been, in recent years, a subject of intense discussion in economics and finance fields. Academics, such as Thaler (1999), Shiller (2000b), Cooper et al. (2001), Ritter and Welch (2002), Ofek and Richardson (2002), Lamont and Thaler (2003), Brunnermeier and Nagel (2004), Cunado et al. (2005), Hong and Stein (2007), Stiglitz (2009), Gutierrez (2011) and Griffin et al (2011), among others, believe these events are associated to asset price bubbles. Actually, the episode is widely known in the media as the Dotcom, the Internet, the Tech bubble, or yet, the Great Internet Stock Bubble (Thaler, 1999).

\footnotetext{
${ }^{1}$ Department of Accounting, University of Brasilia, Brazil. This paper was prepared while this author was visiting scholar at the Nottingham Trent University, UK. Financial support from CAPES is gratefully acknowledged.

${ }^{2}$ Division of Economics, Nottingham Trent University, UK.
} 
Due to the booms and crashes that have characterized the world financial markets during the last decade, including the 2007-2009 financial crises, which brought harmful consequences to most of the world's real economy, the study of bubbles by academic researchers remains on the agenda and will probably stay there in the future. Since the early days of bubble econometric studies, a lot has changed, from simple and basic analysis to increasing sophistication, as statistical and econometric techniques were incorporated in the analysis. In most quantitative studies on the subject, it is common sense that when stock prices deviate from their fundamental value, there is evidence that a bubble has arisen. According to the present value theory of finance, fundamental asset prices are determined by the sum of the present discounted values of expected future dividends. More specifically, stock prices are equal to the present value of rationally expected or optimally forecasted future real dividends discounted by a constant discount rate. This model is often used by economists and investment analysts as a method to explain the behaviour of aggregate market indices (Shiller, 1981). In fact, since market uncertainties and frictions exist, and because the discount rate may vary, it is expected that actual prices fluctuate around fundamental values (LeRoy, 1989).

An increasing number of studies on the subject deal with methods to test for rational bubbles. A rational bubble exists in a stock market if investors are willing to buy stocks for a price that is higher than their suggested fundamental value would indicate. This is considered a rational behaviour as long as these investors expect they can sell these stocks at a higher price in the future. For this reason, the current excessive price becomes an equilibrium price. As long as these expectations hold, stock prices will keep growing, and this explosive growth makes prices to diverge from their fundamental values, nurturing a rational bubble. The bubble keeps growing up to the point where expectations change and investors begin to suspect that the price hike is not sustainable. At this point, any bad news can trigger a panic which leads to the bursting of the bubble ${ }^{3}$.

It has been suggested that persistence shifts in the relationship between stock prices and dividends can be related to the occurrence of rational bubbles in stock markets (Sollis, 2006; Leybourne, Kim and Taylor, 2007; Sanso-Navarro, 2009). New econometric methods have been developed allowing testing for changes in persistence in the order of integration of economic and financial time series. Among them, and in connection to the present paper, we highlight the method developed by Leybourne, Kim and Taylor (2007), hereafter LKT. This method has the purpose of testing for and dating multiple changes in the order of integration of a time series between different trend stationary $(\mathrm{I}(0))$ and difference-stationary (I(1)) regimes and it is based on sequences of doubly-recursive implementations of regressionbased unit root statistics (Elliott et al, 1996).

Since a bubble entails that stock prices deviate from their fundamental values, it has been argued that a nonstationary dividend-price ratio characterizes a bubble process. Therefore, if a dividend-price series suffers a change in persistence from $\mathrm{I}(0)$ to $\mathrm{I}(1)$, this can be considered as an evidence of a bubble. Besides, if the dividend-price ratio changes again to I(0), this would imply that the bubble has collapsed. Sollis (2006) tested for a bubble in S\&P Composite dividend-price ratio using a test for change in persistence developed by Leybourne, Kim, Smith and Newbold (2003) and Kim et al. (2002). In fact, this test is a predecessor to the LKT test as it tests for a single change in persistence only. Besides, as put forward by LKT, "in general, the tests for a single change in persistence will not be consistent against processes which display multiple changes in persistence. Where multiple changes in

\footnotetext{
${ }^{3}$ A recent example of this behaviour is the housing market bubble in the US (2007-2009).
} 
persistence occur these procedures also cannot be used in general to consistently partition the data into its separate $\mathrm{I}(0)$ and $\mathrm{I}(1)$ regimes" (LKT, p. 03). ${ }^{4}$

It should be mentioned that LKT's method was not developed specifically to test for asset price bubbles. Actually, it is intended to test for multiple changes in persistence in time series. But since the existence of bubbles entail changes in persistence in prices, it can be used to suggest the presence of bubbles. Other authors have used the LKT method to test multiple changes in persistence in non-bubble contexts. For example, Noriega and RamosFrancia (2009) use the LKT procedure to test for change in persistence in the US inflation.

A completely different approach to testing for bubbles has been recently proposed by Phillips, Wu and Yu (2011), hereafter PWY. They provide a recursive test procedure which provides a mechanism for testing explosive behaviour, dating the origination and collapse of a bubble (which they refer to as "economic exuberance"), and presenting valid confidence intervals for explosive growth rates. The method involves the recursive implementation of a right-tail unit root test and a supreme test together with a new limit theory for moderately explosive behaviour.

Although the LKT and PWY methods can be used to detect bubbles, they are by no means the only ones which have been used by researchers in recent years ${ }^{5}$.

In this paper, we use the methodology developed by LKT to test for the Dotcom bubble in the NASDAQ and compare the results with PWY's who use their own methodology to test for the same bubble. In other words, the purpose of this paper is to verify whether the methodology developed by LKT, devised to determine changes in persistence, which can be associated to a bubble, is consistent with the methodology developed by PYW to detect explosive behaviour, which also characterizes a bubble. Therefore, the question posed here is: are the PYW and the LKT methods equivalent when applied to detecting bubbles? In other words, can both tests detect the existence of the bubble and are the periods suggested by them coincident?

Besides this introduction, the paper is structured as follows: Section 2 summarises the LKT and the PWY methods; Section 3 describes the data; Section 4 presents the empirical results ; and Section 5 the concluding remarks .

\section{Methodology}

LKT $^{6}$ developed a test for multiple changes in persistence, i.e. in the order of integration of a time series, which allows consistent estimation of the change dates and is also robust to the presence of multiple level breaks. Besides, they show that this test is the only extant methodology which is consistent when multiple changes in persistence take place. The data generation process (DGP) consists of the following Time-Varying (TV) AR(p):

$$
y_{t}=d_{t}+u_{t}, \quad u_{t}=\rho_{i} u_{t-1}+\sum_{j=1}^{k_{j}} \phi_{i j} \Delta u_{t-j}+\varepsilon_{t}, \quad t=1, \ldots, T
$$

where $y_{\mathrm{t}}$ is the series being tested, $d_{t}=z_{t}^{\prime} \beta$ is the deterministic kernel and $\varepsilon_{t}$ is a martingale difference sequence. In Eq. (1), $u_{t}$ is assumed to be a TV $\mathrm{AR}(\mathrm{p})$ process, rewritten such that $k_{i}$ $=p_{i}-1, i=1, \ldots, m+1$, where $m$ is the number of changes in persistence. The null being tested is $\mathrm{H}_{0}: y_{t} \sim(1)$ all over, and the alternative is $\mathrm{H}_{1}: y_{t}$ experiences one or more changes in

\footnotetext{
${ }^{4}$ As put forward by Bai (2000, p. 304), "because a myriad of political and economic factors may alter the data generating process, multiple changes may be a more accurate characterization of economic time series".

${ }_{5}^{5}$ A comprehensive survey on methods which have been used to analyse or detect asset price bubbles can be found in Gürkaynak (2008).

${ }^{6}$ Early versions of the test for a single change in persistence were developed by Harvey et al. (2006) and

Leybourne et al. (2006)
} 
persistence between $\mathrm{I}(1)$ and $\mathrm{I}(0)$ or vice-versa. Under $\mathrm{H}_{1}, \rho_{i}$ is subject to $m \geq 1$ unknown persistence changes, producing $m+1$ segments with change points given by $\tau_{1}<\tau_{2}<\ldots<\tau_{\mathrm{m}-1}<\tau_{\mathrm{m}}$. The procedure divides $y_{t}, \mathrm{t}=1, \ldots, T$ into separate $\mathrm{I}(0)$ and $\mathrm{I}(1)$ regimes, and consistently estimates the change points. LKT define the fraction $\tau \in(\lambda, 1)$, for a given $\lambda$ in $(0,1)$, and base their test $\mathrm{H}_{0}$ vs. $\mathrm{H}_{1}$ on the local GLS de-trended ADF unit root statistic, that uses the sample observations between $\lambda T$ and $\tau T$, called $\operatorname{DFG}(\lambda, \tau)$, obtained as the standard $\mathrm{t}-$ statistic associated with $\hat{\rho}_{i}$ in the fitted regression

$$
\Delta y_{t}^{d}=\hat{\rho}_{i} y_{t-1}^{d}+\sum_{j=1}^{k_{i}} \hat{b}_{i, j} \Delta y_{t-j}^{d}+\hat{\varepsilon}_{t}, \quad t=\lambda T, \lambda T+1, \ldots, \tau T
$$

with $y_{t}^{d} \equiv y_{t}-z_{t}{ }^{\prime} \hat{\beta}$ and $\hat{\beta}$ the OLS estimate of $\beta$ in the regression of $y_{\lambda, T}$ on $z_{\lambda, T}$, where $y_{\lambda, T} \equiv\left(y_{\lambda T}, y_{\lambda T+1}-\bar{\alpha} y_{\lambda T}, \ldots, y_{\tau T}-\bar{\alpha} y_{\tau T-1}\right)^{\prime}$ and $z_{\lambda, T} \equiv\left(z_{\lambda T}, z_{\lambda T+1}-\bar{\alpha} z_{\lambda T}, \ldots, z_{\tau T}-\bar{\alpha} z_{\tau T-1}\right)^{\prime}$, with $\bar{\alpha}=1+\bar{c} / T$, and $\bar{c}<0$. The test is based on doubly-recursive sequences of DF type unit root statistics $M \equiv \inf _{\lambda \in(0,1)} \inf _{\tau \in(\lambda, 1)} D F_{G}(\lambda, \tau) \quad$ with corresponding estimators given by $(\hat{\lambda}, \hat{\tau}) \equiv \arg \inf \lambda \in(0,1) \inf \tau \in(\lambda, 1) \operatorname{DFG}(\lambda, \tau)$.

Application of the $M$ test yields the start and end points (i.e. the interval $[\hat{\lambda}, \hat{\tau}]$ ) of the first $\mathrm{I}(0)$ regime over the whole sample. The presence of any further $\mathrm{I}(0)$ regimes are detected sequentially by applying the $M$ statistic to each of the resulting subintervals $[0, \hat{\lambda}]$ and $[\hat{\tau}, 1]$. Continuing in this way, all $\mathrm{I}(0)$ regimes together with their start and end points can be identified. The period between the end point of one $\mathrm{I}(0)$ regime and the start point of the next $\mathrm{I}(0)$ regime corresponds to an $\mathrm{I}(1)$ regime.

The PWY method allows both to detect explosiveness in the bubble process and to locate the starting and ending date of the bubble. Their method consists in implementing right-tailed unit root tests in a recursive way. The tests were developed as follows. Given a time series $x_{t}$ (log stock price or log dividend), the augmented Dickey-Fuller (ADF) test for a unit root is applied against the alternative of an explosive root (right-tailed test). That is,

$$
x_{t}=\mu_{x}+\delta x_{t-1}+\sum_{j=1}^{J} \phi_{j} \Delta x_{t-j}+\varepsilon_{x, t}, \quad \varepsilon_{x, t} \sim N I D\left(0, \sigma_{x}^{2}\right)
$$

is estimated by OLS for a certain number of lags $J$. Significance tests or some information criterion can be used to determine the lag parameter $J$. The unit root null hypothesis is $\mathrm{H}_{0}: \delta=$ 1 and the right-tailed alternative hypothesis is $\mathrm{H}_{1}: \delta>1$. Then, in forward recursive regressions, Eq. (3) is estimated repeatedly, using subsets of the sample data which are incremented by one observation at each run. If the first regression involves $\tau_{0}=\left[n r_{0}\right]$ observations, for some fraction $\tau_{0}$ of the total sample, where [ ] represents the integer part of the argument, successive regressions employ this originating data set supplemented by successive observations giving a sample of size $\tau=[n r]$ for $r_{0}<r<1$. Denote the corresponding t-statistic by $A D F_{r}$ and hence $A D F_{1}$ corresponds to the full sample. Thus, under the null,

$$
A D F_{r} \Rightarrow \frac{\int_{0}^{r} \tilde{W} d W}{\left(\int_{0}^{r} \tilde{W}^{2}\right)^{1 / 2}} \quad \text { and } \quad \sup _{r \in\left[r_{0}, 1\right]} A D F_{r} \Rightarrow \sup _{r \in\left[r_{0}, 1\right]} \frac{\int_{0}^{r} \tilde{W} d W}{\left(\int_{0}^{r} \tilde{W}^{2}\right)^{1 / 2}}
$$

where $W$ is the standard Brownian motion and $\tilde{W}(r)=W(r)-\int_{0}^{1} W$ is demeaned Brownian motion. Comparing $\sup _{\mathrm{r}} A D F_{r}$ with the right tailed critical values from 
$\sup _{r \in\left[r_{0}, 1\right]} \int_{0}^{r} \tilde{W} d W /\left(\int_{0}^{r} \tilde{W}^{2}\right)^{1 / 2}$ provides a test for a unit root against explosiveness, which characterizes a bubble. To locate the origin and the conclusion of exuberance, one can match the time series of the recursive test statistic $\mathrm{ADF}_{r}$, with $r \in\left[r_{0}, 1\right]$, against the right tailed critical values of the asymptotic distribution of the standard Dickey-Fuller t-statistic. In particular, if $r_{e}$ is the origination date and $r_{f}$ is the collapse date of explosive behaviour in the data, estimates of these dates are obtained as:

$$
\hat{r}_{e}=\inf _{s \geq r_{0}}\left\{s: A D F_{s}>c v_{\beta_{n}}^{a d f}(s)\right\}, \quad \hat{r}_{f}=\inf _{s \geq \hat{r}_{e}}\left\{s: A D F_{s}<c v_{\beta_{n}}^{a d f}(s)\right\}
$$

where $c v_{\beta_{n}}^{\text {adf }}(s)$ is the right-tail critical value of $\mathrm{ADF}_{\mathrm{s}}$ with a significance level of $\beta_{n}$.

\section{The Data}

The data utilised in this study consists of the series of monthly data on the NASDAQ dividend-price ratio and the NASDAQ composite price index obtained from Datastream International for the period from February 1973 to December 2011, with 467 observations. The real NASDAQ composite price index was obtained by deflating the nominal price index by the US CPI index available on the US Department of Labour Statistics' website. The real NASDAQ composite dividend index was calculated based on the NASDAQ composite dividend-price ratio and the NASDAQ composite nominal price index and then deflated by the US CPI index. The LKT tests are applied to the natural $\log$ of the series. Table 1 summarises the descriptive statistics for the raw data and its natural logarithm.

Table 1: Summary of descriptive statistics for the NASDAQ dividend-price ratio

\begin{tabular}{|l|r|r|r|r|}
\hline & Real price index & Real dividend index & d-p ratio & Log(d-p ratio) \\
\hline Mean & 227.809 & 111.455 & 1.599 & 0.199 \\
\hline Median & 153.238 & 98.427 & 1.160 & 0.148 \\
\hline Maximum & 985.482 & 271.887 & 5.010 & 1.611 \\
\hline Minimum & 39.198 & 61.189 & 0.170 & -1.771 \\
\hline Std. Dev. & 173.181 & 38.703 & 1.178 & 0.756 \\
\hline Skewness & 1.233 & 1.460 & 1.027 & -0.109 \\
\hline Kurtosis & 4.774 & 5.067 & 2.838 & 2.510 \\
\hline Jarque-Bera & 179.258 & 248.737 & 82.67 & 5.595 \\
\hline Probability & 0.000 & 0.000 & 0.000 & 0.060 \\
\hline Observations & 467 & 467 & 467 & 467 \\
\hline
\end{tabular}

It can be seen that the distribution of the real price and the real dividend indices are positively skewed, leptokurtic and strongly non-normal. The raw data series of the dividendprice ratio has a positive skewness, meaning that most of the data are concentrated below the mean of 1.6. The distribution is also slightly platykurtic. The series of log data is slightly skewed to the right and also slightly platykurtic. At the $10 \%$ level, both series reject the null of normality.

\section{Empirical Results}

In this empirical application, we follow Noriega and Ramos-Francia (2009) and set $\lambda=1 / \mathrm{T}$ such that $\lambda \mathrm{T}=1$. As in LKT we make $\tau=0.20$. For determining the value of $k_{i}$, we use the BIC, which defines the appropriate lag length for values of $k_{i}$ between 0 and 12, for every sample or sub-sample regression computed. We report the results obtained for the version of the test with an intercept and a linear time trend, since the application of the test with no 
intercept and no time trend could not find any $\mathrm{I}(0)$ regime inside the series tested ${ }^{7}$. The $\mathrm{M}$ test is initially applied over the whole sample (February 1973-December 2011), detecting an interior I(0) regime between August 2001 and December 2011, in which the unit root null is rejected at the $1 \%$ level (the $M$ statistic is -5.574 and the critical value from LKT for $\mathrm{T}=467$ is -5.078 at the $1 \%$ level).

The test is then applied over February 1973-July 2001 (342 observations) and we find a second I(0) regime between July 1992 and November 1998, with the null being rejected at the 5\% level (M statistic $=-4.756$; critical value at 5\%=-5.159). Applying the test over the remaining periods of February 1973-June 1992 and December 1998-July 2001 results in not rejecting the null, meaning that we cannot find any other $\mathrm{I}(0)$ regime, which leads to the conclusion that these are I(1) regimes. The results are summarised in Table 1.

Table 2: Results of the LKT test for the NASDAQ dividend-price ratio

\begin{tabular}{|c|c|c|c|c|c|c|c|c|}
\hline \multicolumn{2}{|c|}{ Period Tested } & \multicolumn{2}{|c|}{ Result } & \multirow{2}{*}{ Regime } & \multirow{2}{*}{$\begin{array}{l}\text { Duration } \\
\text { (months) }\end{array}$} & \multirow{2}{*}{$\hat{k}_{i}$} & \multirow[t]{2}{*}{ M } & \multirow{2}{*}{ Crit. Value } \\
\hline Start & End & Start & End & & & & & \\
\hline 1973:02 & 2011:12 & 2001:08 & 2011:12 & $\mathrm{I}(0)$ & 125 & 12 & -5.574 & $-5.078(1 \%)$ \\
\hline 1973:02 & 2001:07 & 1992:07 & 1998:11 & $\mathrm{I}(0)$ & 78 & 2 & -4.756 & $-4.667(5 \%)$ \\
\hline 1973:02 & 1992:06 & - & - & $\mathrm{I}(1)$ & 234 & 10 & -3.677 & $-4.422(10 \%)$ \\
\hline 1998:12 & 2001:07 & - & - & $\mathrm{I}(1)$ & 32 & 12 & -4.113 & $-5.459(10 \%)$ \\
\hline
\end{tabular}

Table 3 shows, for the whole sample period and for each period identified as $\mathrm{I}(0)$ or I(1), summary statistics and estimates of $\rho_{i}$. The first row shows the statistics for the whole period, i.e. February 1973-December 2011. It can be seen that for the I(1) period of December 1998-July 2001 the values for the mean and standard deviation were the lowest, indicating that in this period the dividend-price ratio was low and had low volatility. On the other hand, the I(1) period of February 1973-June 1992 present the greatest values for the mean and standard deviation, revealing a period with high dividend-price ratio and high volatility.

Table 3: Statistics and estimates of the AR parameter $\left(\hat{\rho}_{i}\right)$

\begin{tabular}{|c|c|c|r|c|r|r|r|r|}
\hline \multicolumn{2}{|c|}{ Series/sample } & \multirow{2}{*}{ Mean } & $\begin{array}{c}\text { Standard } \\
\text { deviation }\end{array}$ & $\begin{array}{c}\text { Order of } \\
\text { Integration }\end{array}$ & Kurtosis & Skewness & $\begin{array}{c}\text { Jarque-Bera } \\
\text { (p-value) }\end{array}$ & $\hat{\rho}_{i}$ \\
\hline Start & End & & 1.178 & $\mathrm{I}(1)$ & 2.838 & 1.027 & 0.000 & 0.988 \\
\hline $1973: 02$ & $2011: 12$ & 1.596 & 1.000 & 0.955 \\
\hline $1973: 02$ & $1992: 06$ & 2.446 & 1.120 & $\mathrm{I}(1)$ & 1.723 & 0.303 & 0.000 & 0.953 \\
\hline $1998: 12$ & $2001: 07$ & 0.285 & 0.077 & $\mathrm{I}(1)$ & 1.557 & -0.695 & 0.246 & 0.950 \\
\hline $2001: 08$ & $2011: 12$ & 0.814 & 0.255 & $\mathrm{I}(0)$ & 3.299 & 0.792 & 0.001 & 0.800 \\
\hline $1992: 07$ & $1998: 11$ & 0.860 & 0.294 & $\mathrm{I}(0)$ & 2.245 & 0.469 & 0.097 & 0.573 \\
\hline
\end{tabular}

Fig. 1 shows the trajectory of real NASDAQ price and dividend ratio over the sample period, with the depiction of the $\mathrm{I}(0)$ and $\mathrm{I}(1)$ regimes. It can be seen that during the first $\mathrm{I}(1)$ regime of February 1973-June 1992 stock prices were constantly below dividends, while in the second I(1) regime of December 1998-July 2001, prices were always above dividends. It becomes apparent that although the dividend-price ratio in both periods is nonstationary, with prices and dividends not following compatible trajectories, the situation is quite different in each one. While in the period of February 1973-June 1992 the price index is undervalued, since it remains below dividends throughout the period, in the period of December 1998-July 2001 stock prices rise steeply and diverge strongly and upwards from dividends, reaching a peak in February 2000.

\footnotetext{
${ }^{7}$ These results are available from authors on request.
} 
Fig. 1: Results of the LKT test and the NASDAQ price and dividend indices

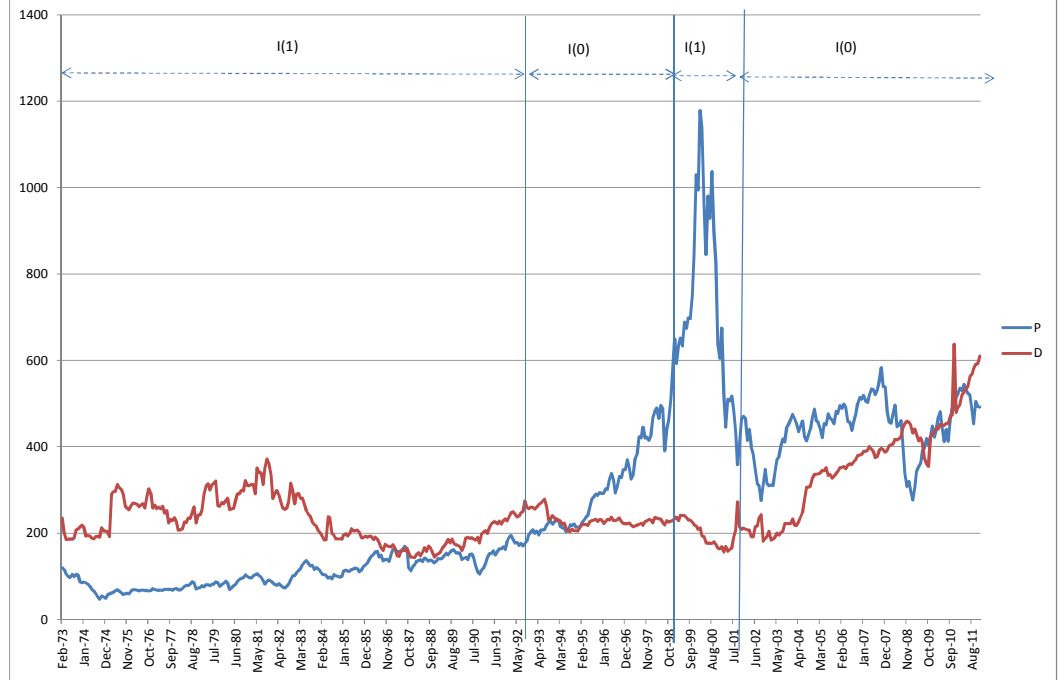

Immediately after this peak, prices fall abruptly and reach a normal level by June 2001. It should be mentioned that the first I(1) period may have started earlier than 1973:02, but dividend-price ratio data for previous periods were not available. Fig. 2 reports the dividend-price ratio and its inverse, the price-dividend ratio, over the sample period showing the $I(0)$ and $I(1)$ regimes, with both series being normalised as 100 in 1973:02. It can also be seen from Fig. 2 that the dividend-price ratio is very high during the first $\mathrm{I}(1)$ period and falls steadily from the end of this period throughout the first $\mathrm{I}(0)$ period and reaching a minimum during the second I(1) period. The price-dividend path shows how stock prices were depressed with respect to dividends during the first I(1) period, while in the second I(1) period, prices rocketed with respect to dividends.

Combining Figs. 1 and 2, it becomes clear that the dividend-price ratio falls from a high level in the first I(1) period to a minimum in the second I(1) period because by March 1994, stock prices start to climb vigorously, reaching a maximum by February 2000, making the dividend-price ratio to fall to its minimum in the same month.

Fig. 2: The dividend-price ratio and the results of the LKT test

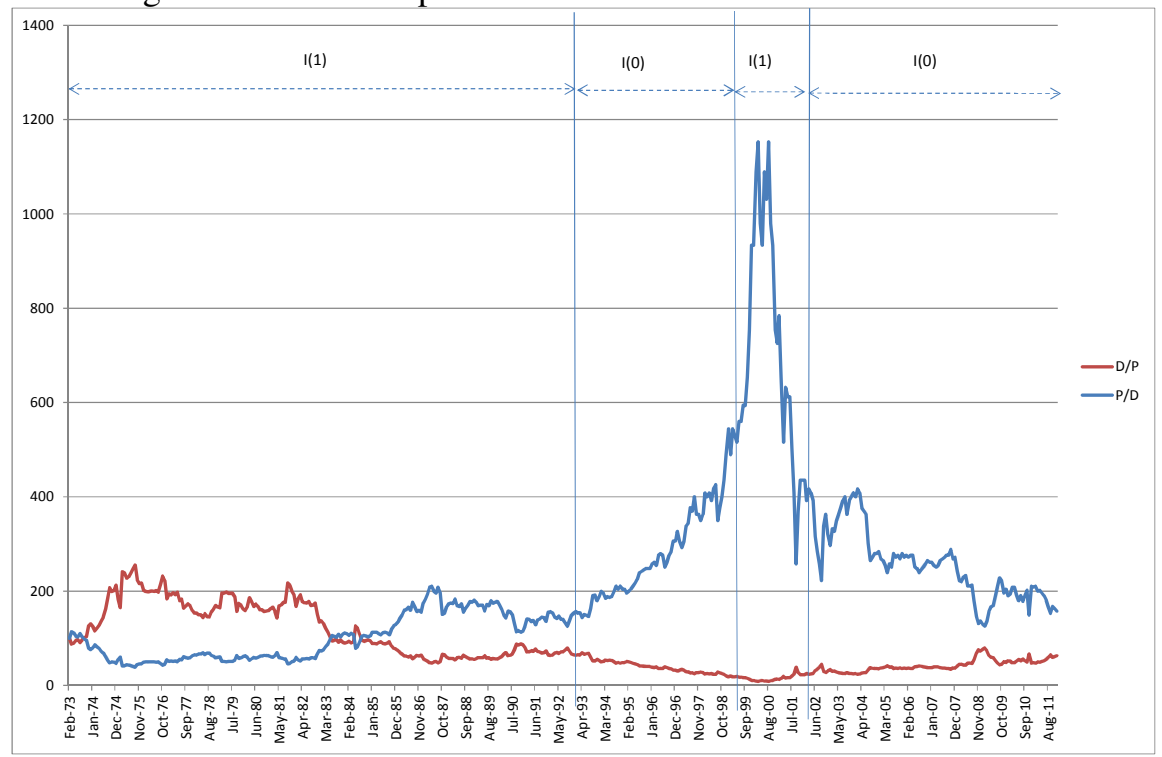


Our interpretation to these results is that in the first I(1) period, NASDAQ was going through a negative bubble, in which stock prices were depressed and did not follow their fundamentals. On the other hand, the second I(1) period is simply a confirmation of the formation and subsequent bursting of the NASDAQ, Dotcom or technological bubble which is well known in the literature.

We now turn to PWY's test for a bubble in NASDAQ. They test separately the real monthly NASDAQ composite price index and the real monthly NASDAQ composite dividend index with a sample covering the period from February 1973 to June 2005, comprising 389 monthly observations. The $\sup _{r \in\left[r_{0}, 1\right]} A D F_{r}$ test provides significant evidence of explosiveness in the price data at the $1 \%$ level, suggesting the presence of a bubble (price exuberance), but no evidence in the dividend data. The dividend series is always nonexplosive. The stock price series is also tested to be non-explosive for the initial sample, which suggests no evidence of a bubble in the initial data. This behaviour persists until June 1995. The test detects the presence of explosive behaviour in the data in July 1995 and the evidence of a bubble becomes stronger hereafter, reaching a peak in February 2000. The bubble lasts until February 2001, and by March 2001 they find evidence that the bubble has collapsed. In April 2001, the evidence of a bubble shows up again and persists until July 2001. In August 2001, no further evidence of a bubble is present in the data. Under the assumption of constant discount rate, PWY consider that the data show sufficient conditions for the presence of bubble. Fig. 3 summarises PWY's ADF test results applied to NASDAQ.

It should be mentioned that a second test for an explosive behaviour in NASDAQ by Phillips and Yu (2010) $)^{8}$ using the same methodology of PWY but with a different sample now extending from January 1990 to January 2009 find different start and end dates for the NASDAQ bubble: June 1995 and November 2000, respectively.

Fig. 3: PWY's results of tests for explosive behaviour in the Log NASDAQ Price and the Log NASDAQ Dividend from April 1976 to June 2005.

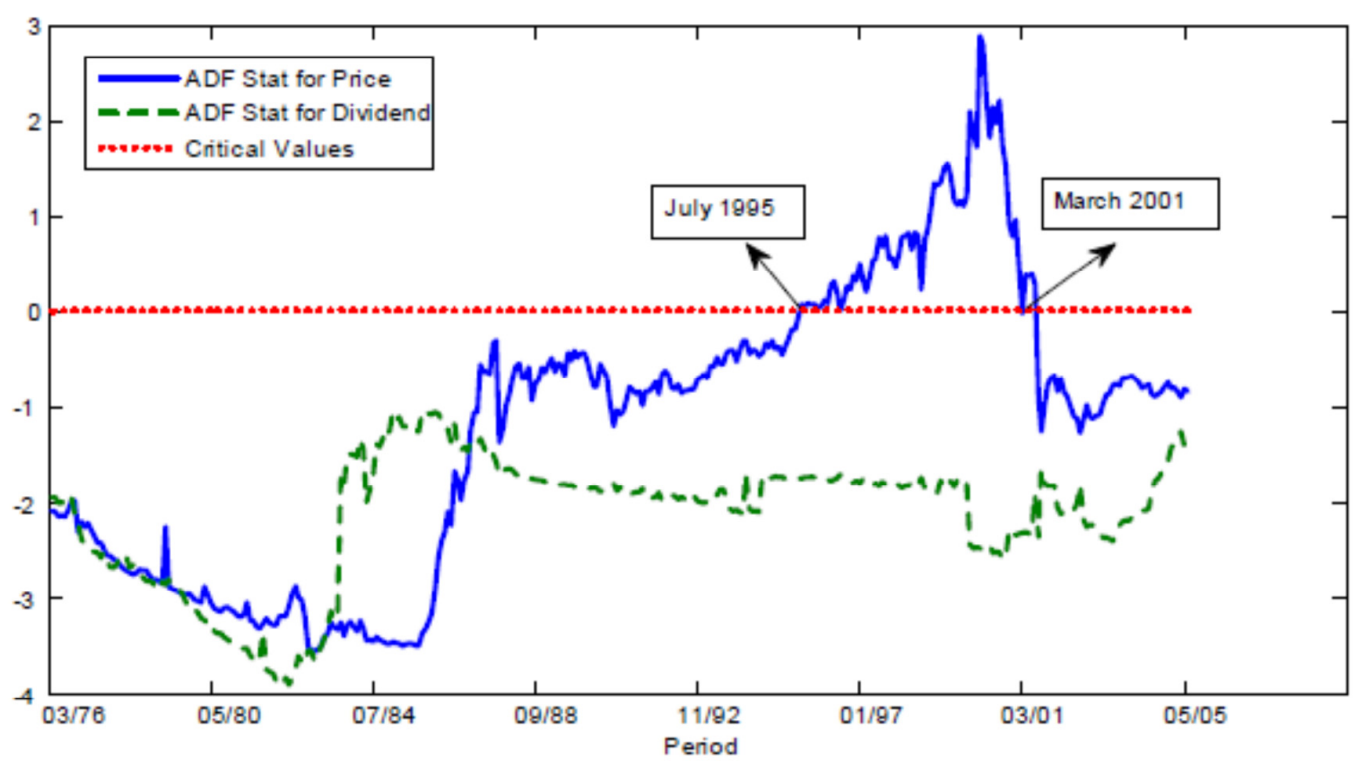

Source: Phillips, Wu and Yu (2011)

\footnotetext{
${ }^{8}$ Notice that although Phillips and Yu's paper is dated as 2010, it is actually posterior to the PWY (2011) paper.
} 
Table 4 summarises the results of testing for bubbles in NASDAQ using LKT's test for change in persistence versus PWY's tests for explosive behaviour. The following remarks are in order. First, the negative bubble found by LKT's method could not be found by PWY's method since the latter is nor suitable to test for depressed prices, i.e. prices that lie below their fundamental values as established by dividends ${ }^{9}$. PWY's method can only find explosive behaviour, which corresponds to positive bubbles.

Table 4. Evidence of bubbles by the LKT and the PWY tests

\begin{tabular}{|l|l|l|l|c|}
\hline Method & Evidence & Start & End & $\begin{array}{c}\text { Duration } \\
\text { (months) }\end{array}$ \\
\hline LKT & Negative bubble & $1973: 02$ & $1992: 06$ & 238 \\
\hline LKT & Bubble & $1998: 12$ & $2001: 07$ & 31 \\
\hline PWY & Bubble & $1995: 07$ & $2001: 03$ & 68 \\
\hline PWY & Bubble & $1995: 06$ & $2000: 11$ & 65 \\
\hline
\end{tabular}

Second, both methods are not precise concerning the beginning and end of the bubble. The two tests using the PWY methodology cited in this paper found different dates for the beginning and ending of the Dotcom bubble $\left(3^{\text {rd }}\right.$ and $4^{\text {th }}$ rows of Table 3$)$. Using the LKT method, we also find different starting and ending dates for the bubble when using different sample periods.

Third, it becomes apparent that the LKT's method is less sensitive to the beginning of a bubble, as it only captures the beginning of the bubble as December 1998, when prices have gone quite far from their fundamental values as seen from Fig. 1. This can also be seen by comparing this with the two PWY bubble starting points of July 1995 and June 1995, respectively. If we consider that on average the media registers the Dotcom bubble as starting in April 1997 and ending in June $2003^{10}$, we see that the PWY method picks up the bubble 27 months earlier than it actually happened and the LKT method captures the bubble 20 months later than it actually occurred. On the other side, the LKT method takes longer to identify the end of the bubble, recording it in July 2001 against PWY's bubble endings of March 2001 and November 2000, respectively. Therefore, both methods capture the end of the bubble much earlier than what is recorded by the financial media.

\section{Conclusions}

In this paper, we apply LKT's methodology for finding persistence changes in the NASDAQ dividend-price ratio which would confirm the existence of the so-called Dotcom bubble which occurred in the NASDAQ stock exchange by the end of the 1990s and beginning of the 2000s. LKT's test is based on doubly-recursive sequences of DF type unit root statistics. First, our empirical results show an unexpected negative bubble in NASDAQ spanning from February 1973 to June 1992. This means that in this period, the prices of stocks listed on NASDAQ were undervalued with respect to their fundamental values as indicated by dividends. Second, we find a positive bubble ranging from December 1998 to

\footnotetext{
${ }^{9}$ According to Shiller (2003, p. 91), a negative bubble occurs when price movements propel "further downward price movements, promoting word-of-mouth pessimism, until the market reaches an unsustainably low level". Other references to negative bubbles can be found, for example, in Blanchard and Watson (1982), Flood and Roderick (1990), Payne and Waters (2005), and Shiller (2000a).

${ }^{10} \mathrm{See}$, for example, "Here's why the Dot Com bubble began and why it popped". Available at: http://articles.businessinsider.com/2010-12-15/markets/30024102 1 tax-rate-capital-gains-taxes-stockreturn-volatility, accessed on $12^{\text {th }}$ April 2012.
} 
July 2001 which is reasonably situated around the period were the Dotcom bubble is usually recorded both by the media and academic studies. In fact, most of the financial media records the Dotcom bubble as starting in April 1997 and ending in June 2003.

We the compare our results with LKT's method referring to the positive bubble in NASDAQ with those recorded after application of PWY's method designed to detect positive bubbles characterised by mildly explosive unit roots in NASDAQ price and dividend indices. PWY's method consists in implementing right-tailed unit root tests based on recursive regressions. The first PWY test aimed at finding the NASDAQ bubble finds the bubble starting in July 1995 and ending in March 2001 (PWY). The second PWY test, using a different sample, finds the bubble starting in June 1995 and ending in November 2011 (Phillips and Yu, 2010).

Our conclusion, based on the findings of this paper, is that the LKT and the PWY methods are complementary to each other, as far as positive bubbles are concerned, although they lack precision with respect to the bubble starting and ending dates. The PWY method finds the bubble starting much earlier than the LKT method, but the latter is closer to the average media versions. With respect to the end of the bubble, the differences are much smaller between the findings of the two methods, although both methods find the bubble ending much earlier than what is reported by the media. Finally, it should be mentioned that only the LKT test is capable of finding both positive negative bubbles while the PWY test, by definition, can only find positive bubbles.

\section{References}

Bai, J. (2000). Vector autoregressive models with structural change in regression coefficients and in variance-covariance matrices. Annals of Economics and Finance 1, 303339.

Blanchard, O. J. and Watson, M. W. (1982). Bubbles, Rational Expectations and Financial Markets. In Crises in the Economic and Financial Structure, Paul Wachtel, editor, pp. 295-316. Lexington, MA: D.C. Heathand Company.

Brunnermeier, M. K. and Nagel, S. (2004). Hedge Funds and the Technology Bubble. The Journal of Finance, Vol. 59, No. 5, 2013-2040.

Cooper, M. J., O. Dimitrov, AND P. R. Rau, (2001) "A rose.com by any Other Name," Journal of Finance 56, 2371-88.

Cunado, J., L.A. Gil-Alana and F. Perez De Gracia, (2005). A Test for Rational Bubbles in the NASDAQ Stock Index: A Fractionally Integrated Approach, Journal of Banking and Finance 29, 2633-54.

Flood, R. P. and Hodrick, R.P. (1990). On Testing for Speculative Bubbles. The Journal of Economic Perspectives, Vol. 4, No. 2, pp. 85-101.

Griffin, J. M., Harris, J., Shu, T. and Topaloglu, S. (2011) Who Drove and Burst the Tech Bubble?, Journal of Finance 66(4), 1251-1290.

Gürkaynak, R. S. (2008). Econometric Tests of Asset Price Bubbles: Taking Stock. Journal of Economic Surveys Vol. 22, No. 1, pp. 166-186.

Gutierrez, L., (2011) Bootstrapping asset price bubbles, Economic Modelling, Volume 28, Issue 6, November, Pages 2488-249.

Harvey, D.I., Leybourne, S.J. and Taylor, A.M.R. (2006) Modified Tests for a Change in Persistence, Journal of Econometrics 134, 441.469.

Hong, H. and Stein, J.C. (2007) Disagreement and the Stock Market. Harrison and Jeremy C. Stein. The Journal of Economic Perspectives, Vol. 21, No. 2 (Spring,), pp. 109-128. 
Huddart, Steven J. and Louis, Henock. (2011). Insider Selling, Earnings Management, and the 1990s Stock Market Bubble). Available at SSRN: http://ssrn.com/abstract=912214 or http://dx.doi.org/10.2139/ssrn.912214.

Kim, J., Belaire Franch, J., and Badillo Amador, R. (2002). Corrigendum to "Detection of change in persistence of a linear time series". Journal of Econometrics 109, 389-392.

Lamont, O. A., and R. H. Thaler. (2003). Can the Market Add and Subtract? Mispricing in Tech Stock Carve-Outs, Journal of Political Economy 111, 227-68.

LeRoy, S. F. (1989). Efficient Capital Markets and Martingales, Journal of Economic Literature, Vol. 27, No. 4, pp. 1583-1621.

Leybourne, S., Kim, T. and Taylor, A.M. (2006) CUSUM of squares-based tests for a change in persistence, Journal of Time-Series Ananlysis 20 (3),408-433.

Leybourne, S., Kim, T. and Taylor, A.M. (2007). Detecting multiple changes in persistence. Studies in Nonlinear Dynamics and Econometrics 11 (3), 1-32.

Leybourne, S., Kim, T., Smith, V. and Newbold, P. (2003). Tests for a change in persistence against the null of difference-stationarity. Econometrics Journal. 6(2), 291-311.

Noriega, A.E. and M. Ramos-Francia (2009). The dynamics of persistence in US inflation. Economics Letters 105, 168-172.

Ofek, E., and M. Richardson. (2003). DotCom Mania: The Rise and Fall of Internet Stock Prices," Journal of Finance 58, 1113-37.

Payne, J. E. and Waters, G. A. (2005). REIT markets: periodically collapsing negative bubbles? Applied Financial Economics Letters, Vol. 1, Iss. 2, 2005.

Perez, C. (2009). The double bubble at the turn of the century: technological roots and structural implications. Cambridge Journal of Economics, 33, 779-805.

Phillips, P. C. B., Wu, Yangru and Yu, Jun. (2011). Explosive Behavior in the 1990s NASDAQ: When Did Exuberance Escalate Asset Values? International Economic Review, Vol. 52, No.1.

Phillips, Peter C. B. and Jun Yu. (2010). Dating the Timeline of Financial Bubbles during the Subprime Crisis, Cowles Foundation Discussion Paper No. 1770.

Ritter, J. R. and I. Welch. (2002). A Review of IPO Activity, Pricing, and Allocations, Journal of Finance 57, 1795-828.

Sanso-Navarro, M. (2009). Multiple persistence changes in the S\&P Composite dividendprice ratio. Working paper, Departamento de Análisis Económico, Universidad de Zaragoza. Facultad de Ciencias Económicas y Empresariales.

Shiller, R. J. (1981). Do stock prices move too much to be justified by subsequent changes in dividends? American Economic Review 71, 421-436.

(2000a). Measuring Bubble Expectations and Investor Confidence. The Journal of Psychology and Financial Markets, Vol. 1, No. 1, 49-60

(2000b). Irrational Exuberance. Princeton NJ: Princeton, University Press, 2000.

(2003). From Efficient Markets Theory to Behavioral Finance. The Journal of Economic Perspectives, Volume 17, Number 1, 1, pp. 83-104(22)

Sollis, R. (2006). Testing for bubbles: an application of tests for a change in persistence. Applied Financial Economics 16, 491-498.

Stiglitz, J. E. (2009). The Anatomy of a Murder: Who Killed America's Economy? Critical Review 21(2): 329-339, 2009.

Thaler, R. H. (1999). The End of Behavioral Finance. Financial Analysts Journal, Vol. 55, No. 6, pp. 12-17. 